\title{
Parenting and child anxiety
}

Book or Report Section

Accepted Version

Creswell, C., Murray, L., Stacey, J. and Cooper, P. (2011) Parenting and child anxiety. In: Silverman, W. K. and Field, A.

P. (eds.) Anxiety disorders in children and adolescents. 2nd edition. Cambridge child and adolescent psychiatry.

Cambridge University Press, Cambridge. ISBN 9780521721486 Available at http://centaur.reading.ac.uk/17540/

It is advisable to refer to the publisher's version if you intend to cite from the work. See Guidance on citing.

Publisher: Cambridge University Press

All outputs in CentAUR are protected by Intellectual Property Rights law, including copyright law. Copyright and IPR is retained by the creators or other copyright holders. Terms and conditions for use of this material are defined in the End User Agreement. 


\section{www.reading.ac.uk/centaur}

\section{CentAUR}

Central Archive at the University of Reading

Reading's research outputs online 
IN PRESS (2010)

\title{
ANXIETY DISORDERS IN CHILDREN AND ADOLESCENTS: RESEARCH, ASSESSMENT AND INTERVENTION \\ EDS SILVERMAN \& FIELD
}

\author{
Parenting and child anxiety \\ Cathy Creswell', Lynne Murray ${ }^{1}$, James Stacey ${ }^{2}$ \& Peter Cooper ${ }^{1}$ \\ ${ }^{1}$ School of Psychology and Clinical Language Sciences, University of Reading, UK \\ ${ }^{2}$ Oxford Doctoral Course in Clinical Psychology, Oxford University
}

For correspondence:

Cathy Creswell

School of Psychology and Clinical Language Studies,

University of Reading

Whiteknights

Reading

RG6 6AL

Tel: 01183786667

Fax: 01183786665

Email: c.creswell:reading.ac.uk 
Parenting and child and adolescent anxiety disorders

Intergenerational studies have shown that anxiety disorders commonly run in families (e.g., Noyes, Clarkson, Crowe, Yates \& McChesney, 1987), yet genetic research consistently points to a strong environmental component in the aetiology of childhood anxiety disorders (e.g. Gregory \& Eley, 2007). As such, research attention is increasingly looking to the role of parenting to help explain the intergenerational transmission of anxiety. The aim of this chapter is to review recent evidence and present a model of the influence of parental cognitions, expressed affect and behaviour in the development of anxiety disorders in children and adolescents.

\section{A cautionary note}

A large number of studies conducted over the past two decades have found associations between parenting and youth anxiety; however in many the associations have been of modest magnitude. McLeod, Wood \& Weisz (2006) reported that parenting (as a general construct incorporating rejection and control) accounted for only $4 \%$ of the variance in childhood anxiety. For this reason it is important to consider parental factors as one potential risk or maintenance pathway amongst others. The exact contribution that parental factors make remains unclear for several reasons. First, some parenting factors are likely to be of greater significance to anxiety than others; this review will consider the strength of evidence for the prime candidates that have been subjected to empirical evaluation. Second, methodological factors account for much variation in the degree of association between parenting and youth anxiety reported: high quality, observational assessments of parenting, for example, are typically associated with stronger effects than parent or child reports and stronger associations are found when anxiety diagnoses are established as opposed to when anxiety is assessed by questionnaire (e.g. Mcleod, Wood, \& Weisz, 2007). Third, studies vary in both the parenting dimensions assessed, the operational definitions used (e.g. see sections on parental control/involvement and negativity), and whether assessments are made of specific behaviours or more general 'parenting styles' (which may incorporate a collection of parental behaviours and 
cognitions). Effect sizes may also be influenced by the diagnostic composition of the anxiety disordered participant groups, because specificity issues may be masked through the lumping together of disparate anxiety disorders. (For example, it is plausible that certain parental factors may be particularly pertinent in the case of separation anxiety disorder, e.g. Wood, 2006). Fourth, parental factors are likely to vary in their importance at different stages in children's development and studies vary considerably in the age ranges of participants. Throughout this chapter, to identify participant groups we will use the terms infant (for under 2 years), children (for 2-11 years), adolescents (for $12-18$ years) and youth (for studies including both children and adolescents).

Finally, recent studies have emphasised the importance of interactive effects on the development of childhood anxiety disorder. It is now clear that a particular style of parenting may have a specific impact on one child, and have no such impact on another (e.g., a sibling, see Hudson \& Rapee, 2002); and this is likely to be due to interactions between parenting and a range of other variables, including biological vulnerability and life events/ lifestyle factors (e.g., Murray, Creswell, \& Cooper, 2009). It is also essential to note that the great majority of studies include a single parent (most commonly the mother); and it is not clear, therefore, whether effects found are true for parents or caregivers in general, or are specific to parents of a particular sex or in a particular childcare role. Three questions that are of particular importance here relate to whether mothers and fathers tend to parent in similar ways, whether the impact of particular parental behaviours is the same whether it comes from mothers or father, and whether there are distinctive features of mothers' and fathers' parental interactions that make a specific contribution to the development of child anxiety (e.g., Bögels \& Phares, 2008). The current evidence base is limited but we have considered each of these issues further below.

The intergenerational transmission of anxiety disorders The familiality of anxiety disorders has been well documented from studies of mixed generations (e.g. Noyes et al, 1987) including those focussed on parent-child associations. For example, 'top 
down' studies have consistently demonstrated that offspring of adults with anxiety disorders have an increased risk of anxiety disorder themselves (e.g., Beidel \& Turner, 1997; Biederman et al, 1991; Silverman, Cerny \& Nelles, 1988; Turner et al., 1987; Warner et al., 1995; Weissman et al., 1984). Similarly, 'bottom up' studies have noted the increased prevalence of anxiety disorders amongst parents of children with an anxiety disorder (e.g. Last, Hersen, Kazdin, Francis, \& Grubb, 1987; Last, Hersen, Kazdin, Orvaschel, \& Perrin, 1991; Cooper, Fearn, Willetts, Seabrook, \& Parkinson, 2006). Cooper et al. (2006) conducted diagnostic interviews with 85 parents of children aged 7-12 years presenting at a child anxiety disorders clinic and 45 community controls. They found that mothers of children with anxiety disorders were almost three times more likely to meet criteria for a current anxiety disorder than mothers of the non-anxious control group children. Although only $60 \%$ of fathers were assessed in this study, fathers did not demonstrate an increased prevalence of current anxiety disorders in comparison to community controls, although they did show a raised prevalence of lifetime anxiety disorders.

The development of anxiety in children

It is important that models of the development of anxiety in youth are able to account for the increased prevalence of anxiety disorders amongst children with anxious parents (particularly mothers). They must also, however, be able to explain the occurrence of anxiety disorders in the absence of high parental anxiety. An example of such a model is presented by Murray, Creswell, and Cooper (2009) who distinguish between pathways to child anxiety that are accounted for by parental anxiety (i.e., biological/ genetic vulnerability) and pathways that may occur in the absence of parental anxiety, yet may be more likely to occur where parents are also anxious. These pathways are (i) life style and socialisation factors that increase the youth's perception of increased threat and reduced control in relation to the environment, and (ii) parental responses, such as anxiogenic modelling and information transfer. Murray et al. (2009) also proposed that when youths exhibit signs of anxiety these may be reinforced or maintained by particular parental responses (increased 
involvement and reduced encouragement). These responses may be particularly likely to occur when parents are themselves anxious. In this chapter we focus on the parental aspects of this model, and expand it to incorporate the potential mediating role of parental cognitions in the association between parental anxiety and behaviours, thus highlighting potential targets for prevention and treatment to enhance the efficacy of interventions for anxiety in youth.

\section{Parenting and child anxiety}

Observational studies of parent-youth interactions have identified associations (of varying strengths) between youth anxiety and (i) vicarious learning, (ii) information transfer, (iii) parental involvement (vs. autonomy granting) and (iv) negativity (vs. warmth). Although many studies have reported crosssectional associations (e.g. Gar \& Hudson, 2008; Hudson \& Rapee, 2001; Moore, Whaley \& Sigman, 2004), experimental and longitudinal designs are increasingly being used to address the issue of the direction of effects (e.g., Gerull \& Rapee, 2002; De Rosnay, Cooper, Tsigaras, \& Murray, 2006; Murray, De Rosnay et al., 2008). This is an essential development in the field if independent parental risk factors are to be identified, in contrast to what may potentially be parental responses to chid anxiety, or bi-directional influences (see e.g. Silverman, Jurtines, Pina, \& Jaccard, 2009). Thus, the following discussion pays particular attention to the extent to which conclusions can be drawn regarding the anxiogenic nature of particular parental behaviours.

(i) Vicarious learning

Clinical accounts have long ascribed a role to observational learning in the development of children's fears (for a review see Askew \& Field, 2008). For example, accounts of World War II experiences evidence the extent to which children expressed fears during air raids was closely related to the level of maternal expressed fear (Lewis, 1942). However, although observational studies have the advantage of high levels of ecological validity, they commonly lack sufficient control of other potentially contributing variables. The challenge for researchers is to develop tightly controlled 
methods to examine the direction of effects between parenting and child anxiety, while retaining high levels of ecological validity. The studies of Mineka, Cook and colleagues (e.g. Cook \& Mineka, 1987, 1989, 1990; Mineka \& Cook, 1986, 1993), and recent experimental extensions of this work with human populations (e.g. Gerull \& Rapee, 2002; DeRosnay, Cooper, Tsigaras, \& Murray, 2006), have successfully met this challenge, providing support for a causal effect of modelling on the development of anxiety in children. Mineka, Davidson, Cook \& Keir(1984) demonstrated that (nonsnake-fearful) laboratory reared rhesus monkeys developed persistent fears of snakes and snake-like objects after observing their wild-reared parents' fearful responses to snakes. Further studies demonstrated that these effects were enhanced in relation to stimuli where fear may be of an evolutionary advantage (e.g. snakes, but not flowers; Cook \& Mineka, 1989, 1990).

To extend these findings to human populations, experimental methods have recently been applied. These experiments build on 'social referencing' research with nonclinical populations, which has demonstrated that children's responses to potentially fear provoking stimuli are influenced by observed adult behaviour (see review by Feinman, Roberts, Hsieh, Sawyer, \& Swanson, 1992). Gerull and Rapee (2002), for example, trained mothers to either express fear and disgust to potentially fear provoking toys or display neutral expressions, when in the presence of their toddler (15-20 months) offspring. They found that, in comparison to the benign/ neutral control condition, maternal fear expression led to an increase in their offspring's expressed fear and avoidance of the toys. This effect has been found to extend beyond 'prepared' fear-relevant stimuli. Dubi, Rapee, Emerton, \& Schneiring (2008) found that, following negative maternal expression, toddlers were similarly fearful of fear-irrelevant stimuli (toy mushroom and flower) and fear-relevant ones (spider and snake). De Rosnay et al. (2006) adapted this paradigm to assess the transmission of social fear in infancy (12-14 months). Non-clinical mothers were trained to express either social anxiety (i.e. behaviours based on clinical and empirical descriptions of social phobia) or respond in their usual (non anxious) way when interacting with a stranger. Again, in comparison to the control condition, expression of maternal 
anxiety was associated with increased infant fearfulness, avoidance and reduced positive emotional tone when the infant was approached by the stranger. In this study, a significant interaction was reported with infant temperamental fearfulness (assessed using the Infant Behaviour Questionnaire, a parent report measure of infant activity level, smiling and laughter, fear, distress to limitations, soothability and orienting; Rothbart, 1978, 1981): infants who were rated by their mothers as generally more fearful showed a heightened response to maternal expressed anxiety with the stranger.

Although such experimental designs (e.g., Gerull \& Rapee, 2003; De Rosnay et al., 2006) provide support for a causal effect of maternal modelling, one important limitation arises from the fact that a comparison is being made between how non-anxious mothers usually respond and their trained, anxious, response. In other words, infants might simply be responding with increased wariness to their mother reacting in an unexpected manner within the experimental paradigm. To overcome this limitation, it is essential to extend these findings to naturalistic studies. With regards to maternal modelling of anxiety, consistent results have been obtained in a recent prospective longitudinal study (Murray, De Rosnay et al., 2008). A sample of women diagnosed with social phobia and a non-anxious control group were recruited in pregnancy. The women and their children were then serially assessed. When the children were 10 and 14 months of age, mothers conversed with a stranger in the presence of their infant and the infant's subsequent responses to the stranger were rated. Maternal expressed anxiety at 10-months postpartum (which was, as expected, higher in the social phobia group than the control group) predicted increased infant avoidance of a stranger four months later. Again, infant temperament moderated the association: specifically, where infants of mothers with social phobia were behaviourally inhibited (classified on the basis of behavioural observations; Kagan, Reznick, \& Snidman, 1987)(see Chapter 9), they were particularly likely to show increased avoidance of the stranger. Boys appeared more vulnerable than girls to the effects of the mother's disorder. Further longitudinal follow-up of the children participating in this longitudinal study will be important to ascertain whether these factors constitute risk for the development of an 
anxiety disorder in later life. Nonetheless, the current findings provide strong support for the hypothesis that observed maternal anxiety influences the development of childhood anxiety, particularly in the context of pre-existing vulnerability (i.e. high behavioural inhibition).

(ii) Information transfer

A large body of research with nonclinical samples has demonstrated that children's anxious beliefs and behaviours are influenced by verbal information - for example, through tuition, spontaneous conversations, recollections of past event, as well as plans for the future (Fivush, 1991; Nelson, 1993; Denham et al., 1994). In a series of studies with nonclinical samples, Field and colleagues have shown that children's avoidant behaviours and fear beliefs are influenced by the information they are given (e.g. Field Hamilton, Knowles, \& Plews, 2003; Field, Lawson \& Banerjee, 2008; Field \& Lawson, 2003; Lawson, Banerjee \& Field, 2007; and see Chapter 10, this volume) .

Parents are likely to be an important source of fear-relevant information. Observational studies of children with anxiety disorders in conversation with their parents support the view that parental narratives can be an important influence on the development of children's anxiety. For example, Barrett, Rapee, Dadds \& Ryan (1996) instructed parents to discuss ambiguous scenarios with their 7 to 14 year old offspring to help their child generate a plan for how they would respond to the scenarios. Following discussion with their parents, anxious youth were increasingly likely to propose an avoidant plan. In contrast oppositional youth were more likely to propose an aggressive plan; and nonclinical control children were more likely to propose a pro-active plan. Barrett et al. (1996) labelled this the 'FEAR' effect: Family Enhancement of Aggressive or Avoidant Responses. In an accompanying paper, Dadds and Barrett (1996) described the process by which parents of anxious children appeared to support child avoidant responses, specifically by showing enthusiasm for avoidant plans and providing avoidant responses themselves. Similar results were reported by Chorpita, Albano and Barlow (1996) who showed that child trait anxiety correlated positively and significantly with threat interpretations and avoidant plans, and that this was enhanced following 
family discussions. A limitation of these studies is that it is unclear whether parents of anxious children are encouraging their child to adopt a more anxious approach, or are instead encouraging their child (who may try to downplay his or her anxiety) to accurately represent how they would really respond to the scenarios presented. In other words, did parents reinforce anxiety, or did they simply encourage their child to give more accurate responses? To address this difficulty, Murray, Creswell, and Fearon (2010) trained non-anxious mothers of 30 non-anxious children aged 7 to 8 years to act in a manner consistent with the FEAR effect, or in a contrasting manner ('Non-FEAR', i.e. showing enthusiasm for and reciprocating non-threatening interpretations and non-avoidant plans). Following the training period, the children and their mothers discussed two ambiguous scenarios. The children were then assessed on their interpretation of the scenarios that had been discussed, as well as of a novel set of ambiguous scenarios to assess whether the effects of the discussion generalised. Although the non-FEAR group exhibited a reduction in threat interpretation to both the discussed and novel scenarios, the FEAR group exhibited no change in threat interpretation. In other words, family discussions that reinforced children's adaptive (non-FEAR) interpretations led children to adopt and generalise a more adaptive style, whereas discussions that reinforced anxious interpretations maintained this processing style. The combination of findings from the quasiexperimental study of Barrett and colleagues and the experimental study of Murray and colleagues suggests that the discursive style of parents may, indeed, have an influential effect on children's developing fear beliefs.

Future research would benefit from extending these findings to investigate whether these effects lead to changes in observed anxiety when children subsequently enter relevant potentially anxiety provoking situations. Preliminary evidence from a longitudinal study of adjustment to school in children of mothers with social phobia suggests this might be the case (Murray, Pella et al., 2008).

(iii) Parental control 
Theories of the development of anxiety have commonly implicated parental control, in contrast to autonomy granting, as having an important causative role. Specifically, a parent's excessive regulation of the child's behaviours and discouragement of independence is likely to (a) give the child a message that the world is a dangerous and uncontrollable place (e.g., Hudson \& Rapee, 2004), and (b) militate against the child's developing a sense of competence and mastery, reinforcing the avoidance of challenge (Parker, 1983; Chorpita \& Barlow, 1998). Studies have differed in the specific nature of parental control assessed; some focus on parental overinvolvement (where nurturance and support is given to the child when it is not needed, e.g. Hudson \& Rapee, 2001 ); others on intrusive control (where the parent takes over or strongly directs the child, e.g. Wood, 2006); and others on lack of autonomy granting (where a parent fails to encourage the child to face challenges e.g. Moore et al., 2004). In a meta-analytic review, McLeod, et al. (2006) reported overall effect sizes for the general construct of 'control' and for overinvolvement and autonomygranting specifically. Although the overall effect size for control was only $r=.25$ (i.e. accounting for $6 \%$ of the variance), this rose to .42 for autonomy granting (versus .23 for overinvolvement). The authors emphasise the need for the traditional parenting dimensions (such as 'rejection' and 'control') to be dissected into specific components that may represent more specific correlates with child anxiety. Notably, effects were strongest where direct observations of parenting were made (rather than child or parent report), and when child anxiety disorder was examined rather than trait anxiety or anxiety symptom scores.

An important question in relation to parental control is whether it arises in response to child anxiety, or plays an initiating role. Two recent experimental studies have attempted to address this issue. De Wilde and Rapee (2008) instructed 26 mothers of non-clinical children aged 7-13 years to act in either an overly controlling or minimally controlling manner while working with their child on the preparation of a practice speech. Children were subsequently asked to prepare and give a second speech independently of the parent. When children had to do the task alone, those whose mothers had acted in a controlling manner were rated as showing greater anxiety than those whose mothers 
had acted in a minimally controlling manner. A limitation of this study was that the instructions to mothers included the suggestion that they give the child a sense of how likely they were to succeed in the task, so it was unclear to what extent the effects found did arise from differences in maternal control, or from information transfer (see above), or other potentially overlapping parenting behaviours (e.g. negativity).

Support for the influence of parental control on child anxiety was found in a second experimental study. Thirlwall and Creswell (2010) adopted a repeated measures design in which 24 mothers, from a community population, were trained, using verbal instruction and a DVD presentation, to act in (I) a controlling, and (ii) a child-led manner (counterbalanced across participants) while they worked with their 4-5 year old children to prepare to speak to a video-camera. When mothers were more controlling, children predicted that they would be less able to perform well when it came to doing the task; most important, these differences were not accounted for by observed maternal negativity. Furthermore, for children rated as having high trait anxiety, observed child anxiety was significantly higher while delivering the speech when mothers had been controlling (vs child led). Whether a similar pattern of results will be obtained with children of other ages requires exploration; however these preliminary studies suggest that higher levels of maternal control can lead to increases in child anxiety, particularly for children predisposed to being fearful. These conclusions are consistent with those drawn from a longitudinal, naturalistic study in which children who were inhibited at two years of age were only found to be socially reticent at four years of age if their mothers had shown intrusive control or were derisive towards the child at the initial assessment (Rubin, Burgess \& Hastings, 2002). Taken together, these studies support the hypothesis that parental control influences the development of childhood anxiety, and that this effect is exaggerated in the context of vulnerability factors such as high temperamental fearfulness. 
As noted above, parental control has been implicated in the development of anxiety through its influence on children's cognitions about threat and control (e.g. Hudson \& Rapee, 2004; Chorpita \& Barlow, 1998). A recent study by Perez-Olivas, Stevenson and Hadwin (2008) provided preliminary support for the hypothesis that the association between parental control and separation anxiety is mediated by how children process threat information. In this study, 129 non-clinical children (6-14 years) completed a visual search task to assess attentional bias to angry faces, and mothers provided a Five Minute Speech Sample (FMSS). The FMSS involves asking mothers to speak about their child (with minimal prompting) for five minutes; and ratings are then made on the basis of the content and tone of the narratives. The results provided evidence, consistent with a partially mediated pathway, in which the child's vigilance for angry faces, which was associated with maternal overinvolvement, in turn augmented the degree of separation anxiety in the child. Further studies are now required that are able to examine the temporal nature of these associations. Age was not taken in to account in this analysis; however, it is notable that anxiety related differences in hypervigilance for angry faces was only present among children 10 years of age and older, highlighting the need for consideration of processes occurring within narrow age-bands.

In another study, which addresses the cognitive mechanisms by which parental control might influence youth anxiety, Chorpita, Brown, and Barlow (1998) reported that, in a study of 93 clinic and non-clinic children aged 6- 15 years, children's perceived control mediated the association between a measure of control in the family environment and child negative affect (anxiety and depression). Similarly, an observational study by Gordon, Nowicki, and Wichern (1981) provides support for an association between parental over-involvement and children's cognitive style. These researchers administered a difficult puzzle task to 7-8 year old children who were accompanied by their mothers, and found that offspring of mothers who tended to help more, give more directions, and generally interfere more, had a more external locus of control than offspring of less 'controlling' mothers. 
It is important to note, that none of the studies presented thus far provides any information on the impact of child anxiety on parenting behaviour, or potential bidirectional associations. Although we can conclude that there is support for the hypothesis that controlling parenting can influence child anxiety, this does not rule out the possibility of a bi-directional relationship. As noted by Silverman, Kurtines, Pina, and Jaccard (2009), bidirectional influences have rarely been considered in relation to youth anxiety; however, the possibility that parents' behaviour may change towards their child in response, for example, to a child's improvement from treatment, is highly plausible. Consistent with this hypothesis, Rubin, Nelson, Hastings and Asendorpf (1999) reported that parents' perceptions of their child's shyness when aged 2 years, significantly predicted observed maternal overprotection when children were 4 years of age (however, in the absence of an assessment of parenting at 2 years, is unclear whether these results reflect changes over time or a continuity in overprotection). Another approach to disentangling the relative contributions of child and parental influences is to assess parents' responses to multiple offspring with varying levels of anxiety. Hudson and Rapee (2002) and Barrett et al. (2005) both used sibling controls and found no significant difference between nonanxious mothers' behaviour with their anxious child and with the child's sibling; but these two sets of maternal interactions did differ from those of mothers of non-anxious control children. In other words, mothers with an anxious child differed in their parenting to mothers with no anxious children, and their parenting was similar with both their anxious child and that child's sibling. The authors infer from these findings that the distinctive characteristics of the mothers of anxious children, namely, over-involvement (Hudson and Rapee, 2002), and over-control and lack of autonomy granting (Barrett et al., 2005), arise primarily as a function of maternal rather than child characteristics.

Although this interpretation is consistent with their findings, it should be noted that, in Hudson and Rapee (2002) 13\% of anxious children's siblings met criteria for a DSM-IV anxiety or behaviour disorder and 30\% experienced subclinical levels of anxiety. In the study by Barrett and colleagues, 
siblings who met criteria for a clinical-level anxiety disorder were excluded from analyses, however the frequency of subclinical levels of anxiety is not reported and, notably, anxious children and their siblings did not differ in their behaviour within the observed family discussion task. Caution should, therefore, be applied before rejecting the hypothesis that parental behaviours are a response to child anxiety. These studies also highlight the importance of examining interaction effects to explain the development of anxiety in youth, as despite both anxiety disordered children and their siblings experiencing higher levels of parental control, in most cases only one sibling in the pair developed an anxiety disorder. As noted above, parental behaviours are likely to have a differential impact depending on child age and developmental stage. These studies both included children from wide age ranges ( 7 to 16 years, Hudson \& Rapee, 2002; 6 to 16 years, Barrett, Fox \& Farrell, 2005) and included same and mixed sex sibling pairs; however age and sex effects will be an important consideration in future research and neither study was sufficiently powered to look at these variables ( $n=57$ Hudson \& Rapee, 2002; $n=47$ Barrett, Fox \& Farrell, 2005).

A recent study has applied a novel design to further investigate child and maternal contributions to maternal behaviour. Mothers of a sample of 7 to 14 years old children with anxiety disorders and mothers of nonclinical children were observed interacting with an unrelated child from the same diagnostic group as their own child, and an unrelated child from a different diagnostic group (i.e. anxious or not anxious) (Hudson, Doyle, \& Gar, 2009). The anxious and non-anxious children did not differ on mean age or sex. In this study mothers were instructed to help the children prepare to give a speech. All mothers were more involved with clinically anxious children in comparison to nonclinical children, with no significant effects of maternal group, suggesting that the children's anxious behaviours influenced maternal involvement.

In summary, recent experimental studies suggest that increased parental control can lead to increased anxiety (in particular among children prone to high anxiety). In addition, observations of parents of clinically anxious parents interacting with unrelated children suggest that parents may become more controlling or involved in response to high levels of child anxiety. No studies to date 
have been conducted with suitable methodology to fully elucidate the directionality of parental control in relation to anxiety in youth. This is clearly an essential direction for future research.

Parental negativity, or lack of warmth, has been implicated in the development of anxiety as it is suggested that it may lead the child to believe that the environment is fundamentally hostile and threatening, that outcomes will be negative, and to a sense of low self-worth and competence (Parker, 1983; Bogels \& Tarrier, 2006). Although some have suggested that parental negativity may be associated with youth anxiety through their mutual association with low mood (e.g., Rapee, 1997), others have suggested that the experience of parental negativity may create a vulnerability for developing fear through other pathways. Price-Evans and Field (2008) reported that, among a sample of 6-10 year old children, increased child perceptions of mothers as neglectful mediated the effect that verbal threat information (see above and Chapter 10, this volume) had on fear of novel animals. In this study there were no significant effects of child perceptions of punitive maternal style, maternal warmth, overprotection or monitoring or perceptions about paternal rearing. Again, this finding highlights the importance of looking at specific parenting constructs rather than global indices of, for example, 'negativity'. Indeed, the precise definition of parental negativity has differed across studies, and has included withdrawal or a lack of positive affect, but also lack of acceptance, actively aversive parenting or rejection.

Reviews based on both the broader definition and more specific subtypes of parental negativity have concluded that evidence for parental lack of warmth being associated with child anxiety is weak and inconsistent (Wood, et al., 2003; di Bartolo \& Helt, 2007; McLeod, Wood, \& Weisz, 2007). For example, on the basis of their meta-analysis, Mcleod and colleagues reported a small mean effect size of $r=.20$ for the general construct of 'rejection', and, more specifically, mean effect sizes of $r=$ .06 for warmth, .22 for withdrawal, and .23 for aversiveness. In addition, where associations have been found, studies have not been equipped to address issues of directionality. A recent exception is the study of Silverman, Kurtines, Pina and Jaccard (2009). They studied a sample of 7 to 16 year old 
clinically anxious youth before and after CBT treatment, with or without active parental involvement. They assessed their patients' perceptions of parental positive and negative behaviours, and conflict in the parent-youth relationship. From this study, evidence was strongest for the hypothesis that youth anxiety effects parenting; specifically, changes in youth anxiety from pre to post-treatment were associated with reductions in parental negative behaviours at the posttreatment assessment. As this study relied on child reports of parenting variables it is unclear whether the results reflect changes in child perceptions of parenting, rather than actual parenting; however, it is notable that a similar pattern of findings existed for self-reported parental anxiety, i.e. an equivalent change from pre to post-treatment in the CBT with and without active parental involvement conditions.

Hudson, Doyle \& Gar (2009) also observed maternal negativity in their study of mothers of clinically anxious and non-anxious children. Mothers of clinically anxious children (in comparison to mothers of non-anxious children) were less negative in their interactions with nonclinical children compared to their interactions with clinically anxious children. Although caution must be maintained, because the number of negative behaviours expressed was relatively low, the authors suggest that the fact that mothers of non-anxious children are less used to dealing with severely anxious behaviour may enable them to be more warm and positive in their interactions. Once again, the results of both these studies provide a clear impetus in the field to seriously consider child to parent effects, and bidirectional associations.

\section{Wider parenting practices}

Although research interest in parenting outlined above has largely focused on observed parent-child interactions and the assessment of proximal parenting processes, it is important to note that wider parenting practices are also likely to be implicated in the development of child anxiety. Thus, parents' decisions concerning, for example, the use of day care, and family socialisation and recreational activities, all stand to enhance or limit child exposure to potential challenges beyond 
the home, and thereby the opportunity for the child to develop coping skills. Research on these parenting dimensions in the context of youth anxiety is scant (although see Bögels \& BrechmanToussaint, 2006; Chorpita \& Barlow, 1998). Nevertheless, there are grounds for suggesting that this is an important area for investigation, particularly in the pre-school and early school years. For example, in nonclinical samples, in which parents actively foster pre-school social experiences, children show less anxious behaviour, and fewer absences from kindergarten in comparison to children whose parents were less active in fostering social experiences (Ladd, Le Sieur, Profilet \& Duck, 1993; Ladd, \& Hart, 1992; Ladd, \& Price, 1987).

\section{Parental anxiety and parenting behaviours}

If parental behaviours constitute a pathways to intergenerational transmission of anxiety then it is reasonable to expect a greater frequency of those parental behaviours that appear to reinforce child anxiety among parents who themselves experience high levels of anxiety than among low anxious parents. To date there has been only a small number of studies that address this hypothesis.

\section{(i) Vicarious learning}

It seems plausible to assume that children of anxious parents will have increased opportunities for vicarious learning, due to more frequent expression of anxiety by their parents in comparison to children of non-anxious parents. This assumption has been corroborated by findings from Murray et al.'s (2007) longitudinal study of the intergenerational transmission of social anxiety. Mothers and infants were studied from three demographically comparable groups: where the mother had social phobia ( $n=96)$, where the mother had GAD $(n=52)$, and where the mother had no anxiety disorder $(n=54)$. Mothers' behaviours with their 10 week old infants were observed in a face-to-face interaction and in a social challenge (conversation with a stranger). Mothers with social phobia ( $n=$ 84) were no less sensitive than control mothers with no anxiety disorder $(n=89)$ during interactions with their infants; however, mothers with social phobia exhibited significantly more anxiety, 
engaged less with the stranger and were less encouraging of their child's interaction with the stranger than the non-anxious mothers. These differences appeared to be specific to mothers with social phobia, as they were not found among mothers with Generalised Anxiety Disorder (GAD). Furthermore, as reported above, continuing maternal expressed social anxiety at 10 months predicted subsequent infant avoidance of a stranger. Whether these findings extend to parental anxieties in other (non-social) domains warrants empirical examination.

(ii) Information transfer

Few studies have investigated in detail potentially anxiogenic information that highly anxious parents convey to their offspring. In a preliminary investigation, Moore, et al., (2004) observed mother-child interactions in three discussion tasks (an 'ideal person task', a conflict conversation, and an anxiety conversation). The 68 mother-child (7-15 years) pairs formed four groups based on the presence or absence of maternal as well as child anxiety disorder. There was a main effect of maternal anxiety disorder on the extent to which mothers made catastrophic comments, as well as an interaction with child anxiety diagnosis: specifically, when mothers were anxious, catastrophising was present in the majority of dyads; but when mothers were not anxious, catastrophising was elevated in dyads only where the child had an anxiety disorder diagnosis. These findings suggest that, as well as being a response to high child anxiety, a catastrophic narrative style may also be a function of maternal anxiety. These conclusions must be regarded as preliminary as group comparisons were based on small cell sizes (for example, there were only 8 dyads in the anxious mother-non-anxious child group) and, thus, may not be generalisable. In addition, the findings reflect cross-sectional associations and studies that can investigate the direction of effects are required. Recent findings from a follow-up of the prospective, longitudinal study conducted by Murray, DeRosnay et al. (2008) do suggest that anxious (in this case socially phobic) mothers do express more anxious cognitions (e.g., threat attributions) during a naturalistic, picture book, 
narrative interaction with their five-year old children about a potential social challenge (starting school), independent of previously assessed child behavioural inhibition (Murray, Pella, et al., 2008).

(iii) and (iv) Parental control/ involvement and negativity

Although studies of parental behaviours associated with parental anxiety disorder have found increased negativity and reduced autonomy granting (Whaley, Pinto, \& Sigman, 1999), others have not found consistent associations (Ginsburg, Grover \& lalongo, 2004; Turner, Beidel, Roberson-Nay \& Tervo, 2003; Woodruff-Borden et al, 2002). Indeed, because of the family aggregation of anxiety, it remains possible that associations found between parental anxiety and parenting behaviours are, in fact, the result of a shared association with increased child anxiety. The importance of the effect of the child on their parent has been emphasised by the few studies that take in to account both the child and parent anxiety diagnoses. One such study by Moore et al. (2004), suggested that mothers of anxious children, regardless of their own anxiety, were less warm and granted less autonomy in interaction with their child than mothers of non-anxious children. Unfortunately, as noted above, in this study cell sizes were small which limits generalisability of the findings. Nevertheless, Gar and Hudson (2008) conducted a larger study employing a similar design and reported findings consistent with those of Moore et al.'s general conclusions. 155 mothers and their 4-16 year old children participated, again grouped according to the presence or absence of child and maternal diagnosis (with a minimum cell size of $n=28$ ). Based on both observed parent-child interactions (in preparation of a speech) and the Five Minute Speech Sample (FMSS), across the two procedures there was a main effect of child anxiety status on maternal overinvolvement, but not of maternal anxiety status. Mothers of anxious children were also rated as being more negative on the FMSS. In this study, which focussed on maternal control and negativity dimensions, no significant main effects or interaction effects with maternal anxiety were found. It appears, therefore, that more involved or controlling behaviour, and possibly negativity, is a common parental response to having an anxious 
child which (see above) might reinforce child anxiety (in particular, when it occurs in interaction with other vulnerability factors).

Whether parental anxiety increases the likelihood of over-involved or controlling parenting behaviour, thereby promoting the development of child anxiety, cannot be ascertained from thesestudies of already anxious children: Information is required on the processes that occur before the onset of the child anxiety disorder. In fact, the results of prospective longitudinal studies suggest that infant or child inhibition may provoke these parenting styles more readily among anxious, compared to non-anxious, parents. For example, Hirshfeld, Biederman, Brody, Faraone, and Rosenbaum (1997) found that maternal criticism of the child (assessed via the FMSS) was a function of a significant interaction between child behavioural inhibition and maternal anxiety disorder status; that is, within the group of anxious mothers $65 \%$ of those with inhibited children were critical compared to $18 \%$ of those with non-inhibited children. Among non-anxious mothers, by contrast, the prevalence of maternal criticism was similar in those with inhibited and uninhibited children. Similar findings were obtained by Murray, De Rosnay et al. (2008): mothers with social phobia showed low levels of encouragement to their infants to engage with a stranger only if their infant was behaviourally inhibited.

Cognitive mechanisms may underly the association between high parental anxiety and an increased tendency to respond to child symptoms in potentially anxiogenic ways. For example, Rubin, Cheah and Fox (2001) suggest that parental beliefs about child vulnerability may lead to parenting behaviours that strengthen the relationship between child temperamental risk factors and child anxiety. In other words, parents' beliefs (and the behaviour that follows) may determine whether or not temperamentally fearful children develop an anxiety disorder (and see Creswell, Murray \& Cooper, 2010). Indeed, anxious parents, who are more inclined to interpret the world in a threatening manner themselves, have been found to make similar interpretations in relation to situations involving their child (Lester, Field, Oliver \& Cartwright-Hatton, 2008), to predict that their 
child will feel threatened and be more easily distressed (Creswell \& O'Connor, 2006), and to have lower expectations of their own parental control of their child's behaviour (Wheatcroft \& Creswell, 2007); and these effects hold true after accounting for the contribution of child anxiety.

Furthermore, parental predictions of increased child vulnerability appear to lead to more involved parental behaviours. Thus, in a preliminary experimental study, Creswell, O'Connor \& Brewin (2008) allocated mothers of 52 non-anxious children aged 7-11 years to either a 'positive' or 'negative' expectations' group prior to completing a difficult anagram task with their child, in which the parent was led to believe the child would be likely to enjoy, or else be upset by, the task. The results showed that parents who were given negative expectations displayed increased levels of involvement during the task, suggesting that parental expectations about children's vulnerability are associated with more involved parenting behaviours. In this study, the increase in parental involvement that following experimental manipulation was small and did not lead to a significant increase in observed child anxiety. Future studies are required that include a sample that is sufficiently large to detect differences in child anxiety and to examine interactions with child trait anxiety, Nonetheless, based on these studies, one can speculate that targeting parental cognitions may be of particular value in interventions which aim to improve child anxiety by changing parental behaviour.

(v) Wider parenting practices

As noted above family socialisation and use of childcare are likely to influence the development of anxiety in children, and may be affected by the presence of parental anxiety. For example, highly anxious parents may find it challenging to support their child's exposure to potential stressors or may provide only limited naturalistic opportunities for their child to face fears and develop coping skills. Initial support for this hypothesis has come from our prospective study of mothers diagnosed with social phobia, in which infants of non-anxious mothers experienced greater frequency of nonmaternal care between 4 and 24 months of age (Creswell, Murray, \& Cooper, 2010). 
Further investigation of parental anxiety and wider socialisation practices is clearly warranted.

\section{Further issues in research on parenting and child anxiety}

(i) Specificity of effects

Few studies to date have addressed the issues of specificity of effects. Several issues arise. The first concerns the question of whether particular parenting characteristics are uniquely associated with child anxiety disorders, rather than with more general child psychopathology. Second, there is the question of whether there are parenting characteristics that are specifically related to subtypes of both parent and child anxiety disorder. The third question is whether difficulties associated with either parental or child disorders are only manifest in specific, disorder-relevant contexts, or are apparent across situations. With regard to the first issue, studies (e.g. Dumas \& La Freniere, 1993; Dumas et al., 1995; Hudson \& Rapee, 2001) that have used observational methods to compare the parenting of anxious children with that of children with other disorders have produced inconsistent findings. Thus, compared to mothers of aggressive children, those of anxious children have been observed to be both more negative and more controlling (Dumas \& La Freniere, 1993; Dumas et al., 1995); but also to be indistinguishable in terms of negativity and control (Hudson \& Rapee, 2001). The use of more precise definitions of subtypes of parental behaviours within these broad categories, and comparisons with groups experiencing disorders that are commonly comorbid with anxiety, is likely to lead to greater consistency between findings and a clearer understanding of specific risks for childhood anxiety. Both the Virginia Twin Study (Kendler, Myers \& Prescott, 2000) and the Great Smoky Mountain epidemiological study (Shanahan, Copeland, Costello, \& Angold, 2008) are notable for having used multiple informants (youth and parent), and for having carefully controlled for comorbid anxiety, mood and behavioural disorders. The former showed each of cold, over-protective and authoritarian parenting to contribute to offspring anxiety, over and above their 
impact on other child diagnoses; while the latter showed some evidence for over-intrusive parenting being specifically associated with anxiety disorders rather than conduct disorder, Oppositional Defiant Disorder and depression.

The majority of the studies discussed above concerned associations between parenting factors and childhood anxiety in general, grouping together disparate anxiety disorders (most commonly social phobia, GAD, and separation anxiety disorder (SAD), but also, commonly, specific phobias and obsessive compulsive disorder). The issue of the diagnostic specificity of parental risk factors has received scant attention, despite emerging supportive evidence. Of note are the studies reported above concerning vicarious learning. Gerull and Rapee (2002), for example, showed that maternal modelling of fear to potentially fear-provoking objects led to infant expression of fearful and avoidant responses to those specific stimuli, and not to other novel stimuli to which mothers had not expressed fear. Similarly, specific effects on children's social reticence have been observed after mothers expressed anxiety and displayed reduced encouragement in a social setting (DeRosnay et al., 2006; Murray, De Rosnay et al., 2008). Notably, such parental behaviours have been found to be specifically associated with the presence of maternal Social Phobia and not GAD (Murray et al., 2007), suggesting that issues of diagnostic specificity will be important to take into account when considering the risks associated with parental anxiety disorder, as well as the development of child anxiety. A preliminary study of 55 clinically anxious children and their mothers (also assessed for anxiety disorder diagnoses) highlighted a potential clinical implication of this issue (Cooper, Gallop, Willetts \& Creswell, 2008). Specifically, clinically anxious children (aged 7-12 years), with a range of anxiety disorders, whose mothers met criteria for GAD had equivalent treatment outcomes to children of non-anxious mothers, whereas children who had mothers with social phobia did significantly less well following treatment. One possible interpretation of these findings is that mothers with Social Phobia may engage in specific behaviours which militate against positive treatment outcome (e.g. reduced encouragement/autonomy granting, increased fear modelling). 
Results from studies of information transfer conducted with non-clinical populations are consistent with the notion of diagnostically specific effects on fear acquisition. Thus, in the studies of Field and colleagues, children typically show increased fear responses to the specific animal about which they receive negative information, and this effect does not generalise to animals about which they receive no information (e.g. Field et al., 2003; 2008).

Few studies have examined diagnostic specificity in relation to the constructs of parental negativity and control, a notable exception being one reported by Wood (2006). Wood argues that parental intrusiveness may be a specific risk for Separation Anxiety Disorder (SAD) amongst children prone to anxiety, because it promotes reliance on the caregiver, reduces opportunities to experience feelings of mastery, control and self-efficacy, and reinforces clingy behaviour. In Wood's study, the extent of parental intrusiveness was established for 40 6-13 year old clinically anxious children. Intrusiveness was assessed using a composite of observed intrusive physical contact (in the 'belt-buckling task'), parent and child reported degree of parental help with daily routines, and parent perceptions of help required by the child with daily living skills. Parental intrusiveness was significantly associated with severity of SAD (clinician, child and parent reports), but not with severity of social phobia and GAD.

Both the Smoky Mountain and the Virginia twin studies mentioned above examined the question of specificities in children's perceived parenting within the anxiety disorders. Harsh discipline was associated with GAD in the Smoky Mountain study, as was the similar dimension of authoritative parenting in the Virginia study; however, in the latter, over-protection was also a significant factor. In the Smoky Mountain study, no perceived parenting dimension had a significant unique association with social phobia or child SAD, over and above their association with other child disorders, whereas in the Virginia study, all three parenting dimensions assessed (i.e. harsh discipline, authoritative parenting and overprotection) made significant contributions to phobias (including social phobia), independent of effects on other disorders. 
The final issue in relation to specificity is that parents may show particular parenting behaviours only within specific contexts, for example contexts that either the parent or the child (or both) find stressful. Wood's (2006) findings, for example, might have been different if parental intrusiveness had been assessed within a specific social stress task. Murray et al's (2007) findings are consistent with this idea: mothers with social phobia, but not mothers with GAD, differed from controls in key parenting behaviours within social, but not non-social, tasks.

In summary, research findings to date concerning the association between parenting characteristics and child anxiety may have been distorted by a failure to consider issues of specificity - that is, whether parenting characteristics are specifically associated with child anxiety disorders in comparison to child psychopathology generally, whether specific child and parental anxiety disorders are associated with particular behaviours, and whether parenting behaviours are elicited within specific domains (e.g. within particular stressful contexts). It is essential that future research takes account of these issues in order to identify specific targets for prevention and therapeutic intervention for anxious youth.

(ii) Effects of parent sex

As previously noted, the majority of studies conducted to date have either restricted their samples to mothers, or have included too few fathers to be able to look at differential effects of parent sex. While evidence does not clearly show that fathers, unlike mothers, of anxious children have a raised rate of current anxiety disorder (e.g. Cooper et al., 2006), there is evidence that fathers have an increased lifetime history of anxiety disorder when compared to fathers of non-anxious children (Cooper et al, 2006; Martin et al, 1999). This consideration is important because studies have shown that a past history of psychological distress can continue to have an effect on cognitions (e.g. Hollon et al., 1986) and parenting behaviours, even when there is no current disturbance (Stein et al., 1991). In other words, both maternal and paternal behaviours could contribute to the intergenerational transmission of anxiety. The issue resolves to three central questions: (a) do 
mothers and fathers tend to parent in similar ways? (b) Is the impact of particular parental behaviours the same whether it comes from mothers or fathers? And (c) are there distinctive features of mothers' and fathers' parental interactions that make a specific contribution to the development of child anxiety?

In relation to the first issue, few studies have directly addressed associations between both mothers' and fathers' cognitions and/or behaviours and child anxiety disorder. A notable exception is Barrett et al. (1996) in which fathers' and mothers' responses to ambiguous scenarios involving their child were assessed. Results for fathers were consistent with those reported for mothers. In particular, fathers of anxious children expected their children to respond in a more avoidant manner than fathers of non-anxious children. As noted above, however, this study is limited in that it is unclear to what extent the parents were simply representing their child's actual response, rather than evidencing a parental cognitive distortion. In their detailed analysis of parent-child discussions in a subset of families in the above study, Dadds et al. (1996) reported that fathers, like mothers, of clinically anxious children (anxious and aggressive) responded to an avoidant communication from their child with their own avoidant communication. Studies that have assessed children's perceptions of parenting have also found consistent patterns based on ratings of maternal and paternal behaviour. Siqueland, Kendall, \& Steinberg (1996), for example, reported that 9 to 12 year old children with anxiety disorders rated both their mothers and fathers as significantly less accepting than control children. Most important, in this study, children's ratings of parental acceptance were significantly associated with independent observers' ratings of parental warmth. Similarly, Gruner, Muris, \& Merckelbach (1999), in a community sample of 9-12 year old children, found that both (child-reported) maternal and paternal rejection, and control and anxious rearing, were associated with self-reported child anxiety.

In relation to the second issue, there is evidence to suggest that the impact of certain parental behaviours may be similar for both mothers and fathers. For example, Dadds and Barrett (1996) 
found that an avoidant communication pattern between both mothers and fathers and their children was associated with the extent to which children adopted avoidant plans following family conversations. Rubin et al. (1999), who also reported few differences between mothers' and fathers' expressed parenting styles at assessments made when their children were two and four years of age, found equivalent associations for mothers and fathers between perceived child shyness at 2 years and parental encouragement of independence at 4 years.

Despite these indications of equivalence, others have suggested that fathers may also typically take on a different role to mothers, due to biological and socially reinforced characteristics. For example, fathers may be important agents for children to experience boisterous, stimulating and emotionallyarousing play that encourages risk-taking and facing challenges which may buffer against early separation, stranger and novelty anxiety (Bögels \& Phares, 2008). There is some evidence that the parenting behaviours that distinguish anxious and non-anxious children may be different in fathers and mothers, although studies have largely been limited to non-clinical, adolescent samples and rely on measures of perceived parenting. For example, Brakel, van Muris, Bögels and Thomassen (2006) reported that 11-15 year old adolescents' reports of paternal (but not maternal) anxious rearing behaviours were associated with anxiety symptoms. The possibility that there may be specific effects of parental sex depending on child sex has been supported by Bosco, Renk, Dinger, Epstein and Phares (2003) who found that adolescent daughters' (but not sons') reports of fathers', but not mothers', lower acceptance and higher control contributed to increased adolescent anxiety (independent of the association with depression). Similarly, in a sample of older adolescent girls, more negative perceptions of fathers were associated with increased anxiety (Renk, McKinney, Klein, \& Oliveros, 2006). Unfortunately, most studies have not been equipped to identify whether these effects are specific to anxiety, and where comorbid difficulties have been assessed results have suggested that fathers' controlling and rejecting parenting (but not mothers') were associated with child externalising symptoms, and not child social anxiety (Bögels et al, 2001) or shy and anxious behaviour (McCabe, Clark \& Bennett, 1999). 
However, in an important longitudinal study which included observational and parent report measures of father and mother behaviour with their first-born sons (Belsky, Hsieh \& Crinic, 1998), the extent to which fathers, but not mothers, displayed what are traditionally viewed as positive rearing behaviours (sensitive and non-intrusive) was associated with increased inhibition in vulnerable male toddlers (previously classified as inhibited). These findings are contrary to models of the development of anxiety that postulate that higher levels of intrusiveness will be associated with increased child anxiety. The authors consider the possibility that inhibited boys may benefit from fathers who push their child to face challenges (appearing less sensitive), rather than fathers who are more sensitive to their child's vulnerability (and accept and potentially reinforce children's fears and worries). As this study only involved parents and their sons, whether these findings represented a specific effect for boys remains an open question.

Another important consideration is the impact of concordance between maternal and paternal anxiety. The findings to date on this point are highly inconsistent. Merikangas, Avenevoli, Dierker, and Grillon (1999) found that when both parents had an anxiety disorder, their 7-17 year old offspring were nearly twice as likely to have an anxiety disorder than if just one parent has an anxiety disorder. In contrast, Dierker, Merikangas, and Szatmari (1999) found that parental concordance for anxiety and affective disorders did not significantly increase rates of anxiety disorders, again in 7-17 year old offspring, beyond that found in families in which only one parent was affected. Consistent with the latter study, Jorm, Dear, Rodgers and Christensen (2003) reported that although both paternal and maternal affection (as rated by adult offspring) correlated with offspring's reported anxiety symptoms, if mothers' affection was low, offspring continued to report high anxiety even in the presence of high paternal affection, suggesting that paternal affection did not compensate for a lack of maternal affection. However, in a longitudinal study of divorced families, father-adolescent closeness predicted less adolescent anxiety, over and above maternal variables (Summers, Forehand, Armistead, \& Tannenbaum, 1998). 
In summary, evidence is mixed with regard to whether maternal and paternal factors differ in relation to their association with child anxiety, although it has been suggested that fathers may commonly serve a particular role in encouraging risk-taking behaviour, whereas mothers are more commonly responsible for care (Bögels \& Phares, 2008). Further research is clearly warranted in this area, in particular, systematic evaluations of the behaviours of mothers and fathers, with their daughters and sons, using rigorous observational methodologies.

\section{Summary}

Although many limitations remain in our understanding of parenting pathways to the development of childhood anxiety disorder, the evidence reviewed suggests an interplay between several parenting factors, as illustrated in Figure 1, which are likely to be exacerbated by the presence of parental anxiety. First, research on parenting suggests that child anxiety may be promoted by learning processes of modelling and information transfer. We also suggest that wider parenting practices, such as family socialisation and childcare arrangements, may influence the development of child anxiety by supporting or limiting opportunities for exposure to potential stressors. Although these parental behaviours are likely to be exacerbated in the context of parental anxiety, it is important to note that they may occur independently of parental anxiety (e.g. provision of negative information or modelling by other influential sources). Furthermore, some parenting dimensions associated with child disorder appear to be provoked by particular child characteristics, like temperamental fearfulness or, indeed, child anxiety itself. These include behaviours such as overinvolvement or over-protection, lack of encouragement, or autonomy-promotion. We suggest that these behaviours may relate to parental beliefs that the child is vulnerable in the face of a potentially dangerous world. Notably, such cognitions and behaviours are especially likely to arise in parents who are themselves prone to anxiety. These parenting styles initiated by the child's behaviour, also play a role in maintaining child inhibition and anxiety by reinforcing developing child 
cognitions that the world is threatening and that $s / h e$ is not capable of coping with or controlling this threat.

Figure 1 about here.

\section{Clinical implications}

The proposed model has potential implications for the prevention and clinical management of child anxiety disorders. While individual vulnerability factors may not be strong predictors of later anxiety disorder (see e.g. McLeod et al, 2007), identifying children who experience a combination of vulnerability factors (e.g. high temperamental fearfulness and 'anxiogenic' parenting) may allow effective targeting of preventive interventions. Furthermore, the model identifies key parenting practices that are likely to require specific intervention (e.g. reduced encouragement and autonomy granting; see e.g. Wood et al, 2006) and associated parental cognitions, particularly in the context of high parental anxiety. Indeed, the presence of high levels of parental anxiety is likely to be a barrier to optimal child treatment outcome (e.g. Cobham et al, 1998; Creswell, Willetts, Murray, Singhal, \& Cooper, 2008). Findings to date relating to improving outcomes for this group have been intriguing. Cobham et al (1998), for example, reported a significant benefit to children whose anxious parents (in terms of the proportion of children who were diagnostic free post-treatment) who received Parent Anxiety Management in addition to individual child CBT although parents themselves did not appear to evidence a reduction in their own anxiety. It is possible that these parents responded to the intervention by becoming aware of their anxiogenic parenting and changing their parenting behaviours. The suggestion that parental behaviours, rather than parental anxiety per se, may be important in relation to treatment outcome is supported by findings of a preliminary study in which maternal modelling of anxiety during interactions with the child was a significant predictor of child treatment outcome (Creswell et al., 2008). Future studies, which systematically address both parental anxiety and parental behaviours, will help determine whether it is necessary to address parental anxiety itself, or whether it is sufficient to deal only with the parenting consequences of that anxiety. 
References

Askew, C. \& Field, A. (2008). The vicarious learning pathway to fear 40 years on. Clinical Psychology Review, 28, 1249-1265.

Barrett, P.M., Rapee, R.M., Dadds, M.M., \& Ryan, S.M. (1996). Family enhancement of cognitive style in anxious and aggressive children. Journal of Abnormal Child Psychology, 24 (2), 197-203.

Barrett, P.M., Rapee, R.M. \& Dadds, M. R. (1996). Family Treatment of Childhood Anxiety: A Controlled Trial. Journal of Consulting and Clinical Psychology, 64, 333-342.

Barrett, P.M., Fox, T. \& Farrell, L. (2005). Parent-child interactions with anxious children and their siblings: An observational study. Behavior Change, 22, 220-235.

Beidel, D.C. \& Turner, S.M. (1997). At risk for anxiety: I. Psychopathology in the offspring of anxious parents. Journal of the American Academy of Child and Adolescent Psychiatry, 36(7), 918-924.

Belsky, J., Hsieh, K., \& Crinic, K. (1998). Mothering, fathering and infant negativity as antecedents of boys' externalizing problems and inhibition at age 3: Differential susceptibility to rearing experiences? Development and Psychopathology, 10, 301-319.

Biederman, J., Rosenbaum, J. F., Bolduc, E.A., Faraone, S.V. \& Hirshfeld, D. R. (1991). A high risk study of young children of parents with panic disorder and agoraphobia with and without comorbid major depression. Psychiatry Research, 37, 333-348.

Bögels, S. M. \& Brechman-Toussaint, M. L. (2006). Family issues in child anxiety: attachment, family functioning, parental rearing and beliefs. Clinical Psychology Review, 26, 834-856.

Bögels, S., \& Phares, V. (2008). Fathers' role in the etiology, prevention and treatment of child anxiety: A review and new model. Clinical Psychology Review, 28, 539-558.

Bögels, S. M. \& Tarrier, N. (2004). Unexplored issues and future directions in social phobia research. Clinical Psychology Review, 24, 731-736.

Bögels, S. M., van Oostern, A., Muris, P., \& Smulders, D. (2001). Familial correlates of social anxiety in children and adolescents. Behaviour Research and Therapy, 39, 273-287.

Bosco, G. L., Renk, K., Dinger, T. M., Epstein, M. K., \& Phares, V. (2003). The connections between adolescents' perceptions of parents, parental psychological symptoms, and adolescent functioning. Journal of Applied Developmental Psychology, 24, 179-200. 
Brakel, A. M. L., van Muris, P., Bögels, S. M.,\&Thomassen, C. (2006). A multifactorial model for the aetiology of anxiety in non-clinical adolescents: Main and interactive effects of behavioural inhibition, attachment, and parental rearing. Journal of Child and Family Studies, 15, 568-578.

Chorpita B. F. \& Barlow D. H. (1998). The development of anxiety: the role of control in the early environment. Psychological Bulletin, 124, 3-21.

Chorpita, B. F., Albano, A. M., \& Barlow, D. H. (1996). Cognitive processing in children: Relationship to anxiety and family influences. Journal of Clinical Child Psychology, 25, 170-176.

Chorpita, B.F., Brown, T.A., \& Barlow, D.H. (1998). Perceived control as a mediator of family environment in etiological models of childhood anxiety. Behavior Therapy, 29, 457-476.

Cobham, V.E., Spence, S. H., \& Dadds, M. R. (1998). The role of parental anxiety in the treatment of childhood anxiety. Journal of Consulting and Clinical Psychology, 66, 893-905.

Cook, M. \& Mineka, S. (1987). Second-order conditioning and overshadowing in the observational conditioning of fear in monkeys. Behaviour Research and Therapy, 25, 349-364.

Cook, M. \& Mineka, S. (1989). Observational conditioning of fear to fear-relevant versus fearirrelevant stimuli in rhesus monkeys. Journal of Abnormal Psychology, 98, 448-459.

Cook, M. \& Mineka, S. (1990). Selective associations in the observational conditioning of fear in rhesus monkeys. Journal of Experimental Psychology: Animal Behaviour Processes, 16, 372389.

Cooper, P.J., Fearn, V., Willetts, L, Seabrook, H. \& Parkinson, M. (2006) Affective disorder in the parents of a clinic sample of children with anxiety disorders. Journal of Affective Disorder, 93, 205-212.

Cooper, P.J., Gallop, C., Willetts, L., \& Creswell, C. (2008). Treatment response in child anxiety is differentially related to the form of maternal anxiety disorder. Behavioural and Cognitive Psychotherapy, 36, 41-48.

Creswell, C., Murray, L.M., \& Cooper, P.J. (2010). Use of non-maternal care amongst mothers with social phobia: comparisons with non-anxious mothers and associations with child outcomes WCBCT conference, June 26-292010, Boston University.

Creswell, C. \& O'Connor, T. (2006). 'Anxious cognitions' in children: An exploration of associations and mediators. British Journal of Developmental Psychology, 24(4), 761-766. 
Creswell, C., Murray, L.M., \& Cooper, P.J. (2010). Intergenerational transmission of anxious information processing bias. In J. A. Hadwin \& A. P. Field (Eds.), Information Processing Biases in Child and Adolescent Anxiety. Chichester: Wiley-Blackwell.

Creswell, C., O'Connor, T., \& Brewin, C. (2008). The impact of parents' expectations on parenting behaviour: An experimental investigation. Behavioural and Cognitive Psychotherapy, 36, 483490.

Creswell, C., Willetts, L., Murray, L., Singhal, M., \& Cooper, P. (2008). Treatment of child anxiety: An exploratory study of the role of maternal anxiety and behaviours in treatment outcome. Clinical Psychology and Psychotherapy, 15, 38-44.

Dadds, M. R. \& Barrett, P. M. (1996). Family processes in child and adolescent anxiety and depression. Behavior Change, 13, 231-239.

De Rosnay, M., Cooper, P.J., Tsigaras, N. \& Murray, L. (2006) Transmission of social anxiety from mother to infant: an experimental study using a social referencing paradigm. Behavior Research and Therapy, 44, 1165-75

De Wilde, A. \& Rapee, R.M. (2008). Do controlling maternal behaviours increase state anxiety in children's responses to a social threat? A pilot study. Journal of Behavior Therapy and Experimental Psychiatry, 39, 526-537.

Denham, S., Zoller, D. \& Couchard, E. (1994). Socialisation of pre-schoolers emotion understanding. Developmental Psychology, 30, 928-936.

DiBartolo, P.M. \& Helt, M. (2007). Theoretical models of affectionate versus affectionless control in anxious families: a critical examination based on observations of parent-child interactions. Clinical Child and Family Psychology, 10, 253-274.

Dierker, L. C., Merikangas, K. R., \& Szatmari, P. (1999). Influence of parental concordance for psychiatric disorders on psychopathology in offspring. Journal of American Academy of Child and Adolescent Psychiatry, 38, 280-288.

Dumas, J.E., Serketich, W. J. \& LaFreniere, P. J. (1995). "Balance of power": a transactional analysis of control in mother-child dyads involving socially competent, aggressive, and anxious children. Journal of Abnormal Psychology, 104, 104-113.

Dubi, K., Rapee, R.M., Emerton, J.L., \& Schneiring, C.A. (2008). Maternal modelling and the acquisition of fear and avoidance in toddlers: influence of stimulus preparedness and child temperament. Journal of Abnormal Child Psychology, 36 (4), 499-512. 
Dumas, J. E. \& LaFreniere, P. J. (1993). Mother-Child Relationships as Sources of Support or Stress: A Comparison of Competent, Average, Aggressive, and Anxious Dyads. Child Development, 64, 1732-1754.

Feinman, S., Roberts, D., Hsieh, K., Sawyer, D., \& Swanson, D. (1992). A critical review of social referencing in infancy. In S. Feinman (Ed.), Social Referencing and the Social Construction of Reality in Infancy. NY: Plenum Press.

Field, A. P., Lawson, J., \& Banerjee, R. (2008). The verbal threat information pathway to fear in children: The longitudinal effects on fear cognitions and the immediate effects on avoidance behavior. Journal of Abnormal Psychology, 117 (1), 214-224.

Field, A. P. (2006). Is conditioning a useful framework for understanding the development and treatment of phobias? Clinical Psychology Review, 26, 857-875.

Field, A.P., Hamilton, S.J., Knowles, K.A., \& Plews, E.L. (2003). Fear information and social phobic beliefs in children: A prospective paradigm and preliminary results. Behaviour Research and Therapy, 41, 113-123.

Field, A.H., \& Lawson, J. (2003). Fear information and the development of fears during childhood: effects on implicit fear responses and behavioural avoidance. Behaviour Research and Therapy, 41, 1277- 1293.

Fivush, R. (1991). The Social construction of personal narratives. Merrill Palmer Quarterly, 37, 59-82.

Gar, N.S. \& Hudson, J.L. (2008). An examination of the interactions between mothers and children with anxiety disorders. Behaviour Research and Therapy, 46, 1266-1274.

Gerull, F. C. \& Rapee, R. M. (2002). Mother knows best: Effects of maternal modelling on the acquisition of fear and avoidance behaviour in toddlers. Behaviour Research and Therapy, 40, 279-287.

Ginsburg, G. S., Grover, R. L., \& lalongo, N. (2004). Parenting behaviors among anxious and nonanxious mothers: relation with concurrent and long-term child outcomes. Child and Family Behavior Therapy, 26(4), 23-41.

Gregory, A.M. \& Eley, T. C. (2007). Genetic Influences on Anxiety in Children: What we've Learned and Where we're Heading. Clinical Child and Family Psychology Review, 10, 199-212. 
Gruner, K., Muris, P., Merckelback, H. (1999). The relationship between anxious rearing behaviours and anxiety disorders symptomatology in normal children. Journal of Behavior Therapy and Experimental Psychiatry, 30, 27-35.

Hirshfeld, D.R., Biederman, J., Brody, L., Faraone, S. V. \& Rosenbaum, J. F. (1997). Expressed emotion toward children with behavioral inhibition: associations with maternal anxiety disorder. Journal of the American Academy of Child and Adolescent Psychiatry, 36, 910-917.

Hollon, S.D., Kendall, P.C., \& Lumry, A. (1986). Specificity of depressotypic cognition in clinical depression. Journal of Abnormal Psychology, 95, 52-59.

Hudson, J.L., Doyle, A.M., \& Gar, N. (2009). Child and maternal influence on parenting behaviour in clinically anxious children. Journal of Clinical Child and Adolescent Psychology, 38, 256-262.

Hudson, J. L. \& Rapee, R. M. (2001). Parent-child interactions and anxiety disorders: an observational study. Behaviour Research and Therapy, 39, 1411-1427.

Hudson, J. L. \& Rapee, R. M. (2002). Parent-child interactions in clinically anxious children and their siblings. Journal of Clinical Child and Adolescent Psychology, 31, 548-555.

Hudson, J. L. \& Rapee, R. M. (2004). From anxious temperament to disorder: an etiological model of generalized anxiety disorder. In Generalized Anxiety Disorder: advances in research and practice. (ed. R. G. Heimberg, C. L. Turk and D. S. Mennin), Guilford Press: New York. 51-74.

Jorm, A. F., Dear, K. B. G., Rodgers, B., \& Christensen, H. (2003). Interaction between mother's and father's affection as a risk factor for anxiety and depression symptoms. Social Psychiatry and Psychiatric Epidemiology, 38, 173-179.

Kagan, J., Reznick, J., \& Snidman, N. (1987). The physiology and psychology of behavioural inhibition in children. Child Development, 58, 1459-1473.

Kendler, K.S., Myers, J. \& Prescott, C. A. (2000). Parenting and adult mood, anxiety and substance disorders in female twins: an epidemiological, multi-informant, retrospective study. Psychological Medicine, 30, 281-294.

Ladd, G.W., Le Sieur, K.D., Profilet, S.M. \& Duck, S. (1993). Direct parental influences on young children's peer relationships. In Learning about relationships (vol 2), pp152-183. Thousand Oaks, CA: Sage Publications Inc. 
Ladd, G.W. and C.H. Hart (1992). Creating informal play opportunities: are parents' and preschoolers' initiations related to children's competence with peers? Developmental Psychology, 28(6), $1179-1187$.

Ladd, G.W. and J.M. Price (1987).Predicting children's social and school adjustment following the transition from preschool to kindergarten. Child Development, 58, 1168-1189.

Last, C.G., Hersen, M., Kazdin, A.E., Francis, G., Grubb, H.J., (1987) Psychiatric illness in the mothers of anxious children. American Journal of Psychiatry, 144, 1580-1583.

Last, C.G., Hersen, M., Kazdin, A.E., Orvaschel, H. \& Perrin, S. (1991) Anxiety disorders in children and their families. Archives of General Psychiatry, 48, 928-939.

Lawson, J., Banerjee, R. \& Field, A. P. (2007). The effects of verbal information on children's fear beliefs about social situations. Behaviour Research and Therapy, 45, 21-37.

Lester, K. J., Field, A.P., Oliver, S., \& Cartwright-Hatton, S. (2009). Do anxious parents interpretive biases towards threat extend into their child's environment? Behaviour Research and Therapy, $47,170-174$.

Lewis, A. (1942). Incidence of neurosis in England under war conditions. Lancet, 2, 175-183.

Martin, C., Cabrol, S., Bouvard, M.P., Lepine, J.P., \& Mouren-Simeoni, M.P. (1999). Anxiety and depressive disorders in fathers and mothers of anxious school-refusing children. Journal of the American Academy of Child and Adolescent Psychiatry, 38 (7), 916-922.

McCabe, K. M., Clark, R., \& Barnett, D. (1999). Family protective factors among urban African American youth. Journal of Clinical Child Psychology, 28, 137-150.

McLeod, B.D., Wood, J. J. \& Weisz, J. R. (2007). Examining the association between parenting and childhood anxiety: A meta-analysis. Clinical Psychology Review, 27, 155-172.

Merikangas, K. R., Avenevoli, S., Dierker, L., \& Grillon, C. (1999). Vulnerability factors among children at risk of anxiety disorders. Biological Psychiatry, 46, 1523-1535.

Mineka, S. \& Cook (1986). Immunization against the observational conditioning of snake fear in rhesus monkeys. Journal of Abnormal Psychology, 95, 307-318.

Mineka, S. \& Cook, M. (1993). Mechanisms involved in the observational conditioning of fear. Journal of Experimental Psychology, 122, 23-38. 
Mineka, S., Davidson, M., Cook, M. \& Keir, R. (1984). Observational conditioning of snake fear in rhesus monkeys. Journal of Abnormal Psychology, 93, 355-372.

Moore, P.S., Whaley, S. E. \& Sigman, M. (2004). Interactions between mothers and children: impacts of maternal and child anxiety. Journal of Abnormal Psychology, 113, 471-476.

Murray, H., Creswell, C., \& Fearon, P. (2010). An experimental investigation of the FEAR effect in non-clinical children and their mothers. (Manuscript under review).

Murray, L., DeRosnay, M., Pearson, J. Bergeron, C., Schofield, L., Royal-Lawson, M. \& Cooper, P.J. (2008). Intergenerational transmission of maternal social anxiety: the role of the social referencing process. Child Development, 79, 1049-1064.

Murray, L., Cooper, P.J., Creswell, C., Schofield, E., \& Sack, C. (2007). The effects of maternal social phobia on mother-infant interactions and infant social responsiveness. Journal of Child Psychology and Psychiatry, 48(1), 45-52

Murray, L. M., Creswell, C., \& Cooper, P. J. (2009) Anxiety Disorders in Childhood. Psychological Medicine, 39, 1413-1423.

Murray, L. M., Pella, J., Schofield, E., Arteche, A., Royal-Lawson, M., Creswell, C., \& Cooper, P.J. (2008). Intergenerational factors in the development of child psychopathology. BPS developmental section Annual Conference, Sept 1-3 2008, Oxford Brookes University.

Nauta, M.H., Scholing, A., Emmelkamp, P.M., \& Minderaa, R.B. (2003). Cognitive-behavioral therapy for children with anxiety disorders in a clinical setting: No additional effect of a cognitive parent training. Journal of the American Academy of Child and Adolescent Psychiatry, 42, $1270-1278$.

Nelson, K. (1993). The psychological and social origins of autobiographic memory. Psychological Science, 4, 1-8.

Noyes, R., Clarkson, C., Crowe, R.R., Yates, W.R., McChesney, C.M. (1987). A family study of generalized anxiety disorder. American Journal of Psychiatry, 144, 1019-1024.

Parker, G. (1983). Parental overprotection: a risk factor in psychosocial development. Grune and Stratton:New York.

Perez-Olivas, G., Stevenson, J., \& Hadwin, J. (2008). Do anxiety-related attentional biases mediate the link between maternal over involvement and separation anxiety in children? Cognition and Emotion, 22, 509-521. 
Price-Evans, K. \& Field, A.P. (2008). A neglectful parenting style moderates the effect of the verbal threat information pathway on children's heart rate responses to novel animals. Behavioural and Cognitive Psychotherapy, 36, 473-482.

Rapee, R. M. (1997). Potential role of childrearing practices in the development of anxiety and depression. Clinical Psychology Review, 17, 47-67.

Renk, K., McKinney, C., Klein, J., \& Oliveros, A. (2006). Childhood discipline, perceptions of parents, and current functioning in female college students. Journal of Adolescence, 29, 73-88.

Rothbart, M. K. (1981). Measurement of temperament in infancy. Child Development, 52, 569-578.

Rothbart, M. K. (1986). Longitudinal observation of temperament. Developmental Psychology, 22(3), 356-365.

Rubin, K.H., Burgess, K. B. \& Hastings, P. D. (2002). Stability and social-behavioral consequences of toddlers' inhibited temperament and parenting behaviors. Child Development, 73, 483-495.

Rubin, K.H., Cheah, C.S.L., \& Fox, N. (2001). Emotion regulation, parenting and display of social reticence in preschoolers. Early Education and Development, 12(1), 97-115.

Rubin, K.H., Nelson, L.J., Hastings, P.D., \& Asendorpf, J.B. (1999). The transaction between parents' perceptions of their children's shyness and their parenting styles. International Journal of Behavioral Development, 23, 937-957.

Shanahan, L., Copeland, W., Costello, E. J. \& Angold, A. (2008). Specificity of putative psychosocial risk factors for psychiatric disorders in children and adolescents. Journal of Child Psychology and Psychiatry, 49, 34-42.

Silverman, W.K., Cerny, J.A., \& Nelles, W.B. (1988). The familial influence in anxiety disorders: studies of the offspring of patients with anxiety disorders. In B. B. Lahey \& A. Kazdin (Eds), Advances in Clinical Child Psychology, Vol 11. New York, NY, US: Plenum Press, pp 223-248.

Silverman, W.K., Kurtines, W.M., Pina, A.A., \& Jaccard, J. (2009). Directionality of change in youth anxiety treatment involving parents: An initial examination. Journal of Consulting and Clinical Psychology, 77, 474-485.

Siqueland, L.,Kendall, P. C.,\&Steinberg, L. (1996). Anxiety in children: Perceived family environments and observed family interaction. Journal of Clinical Child Psychology, 25, 225-237.

Stein, A., Woolley, H., Murray, L., Cooper, P., et al (2001). Influence of psychiatric disorder on the controlling behaviour of mothers with 1-year-old infants: A study of women with maternal 
eating disorder, postnatal depression and a healthy comparison group. British Journal of Psychiatry, 179, 157 - 162.

Summers, P., Forehand, R., Armistead, L., \& Tannenbaum, L. (1998). Parental divorce during early adolescence in Caucasian families: The role of family process variables in predicting the longterm consequences for early adult psychosocial adjustment. Journal of Consulting and Clinical Psychology, 66, 327-336.

Thirlwall, K. \& Creswell, C. (2010). The impact of maternal control on children's anxious cognitions, behaviour and affect: An experimental study. Behaviour Research and Therapy (in press).

Turner, S.M., Biedel, D.C. \& Costello, A. (1987) Psychopathology in the offspring of anxiety disordered patients. Journal of Consulting and Clinical Psychology, 55, 229-235.

Turner, S. M., Beidel, D. C., Roberson-Nay, R., \& Tervo, K. (2003). Parenting behaviours in parents with anxiety disorders. Behaviour Research and Therapy, 41(5),541-554.

Warner, V., Mufson, L \& Weissman, M.M. (1995) Offspring at low and high risk for depression and anxiety: mechanisms of psychiatric disorder. Journal of the Academy of Child and Adolescent Psychiatry, 34, 786-797.

Weissman, M.M., Leckman, J.F., Merikangas, K.R., Gammon, G.D. \& Prusoff, B.A. (1984). Depression and anxiety disorders in parents and children. Archives of General Psychiatry, 41, 845-852.

Whaley, S.E., Pinto, A. \& Sigman, M. (1999). Characterizing interactions between anxious mothers and their children. Journal of Consulting and Clinical Psychology, 67, 826-836.

Wheatcroft, R. \& Creswell, C. (2007). Parental cognitions and expectations of their preschool children: The contribution of parental anxiety and child anxiety. British Journal of Developmental Psychology, 25, 435-441.

Wood, J.J., McLeod, B. D., Sigman, M., Hwang, W. \& Chu, B. C. (2003). Parenting and childhood anxiety : theory, empirical findings, and future directions. Journal of Child Psychology and Psychiatry, 44, 134-151.

Wood, J.J. (2006). Parental intrusiveness and children's separation anxiety in a clinical sample. Child Psychiatry and Human Development, 37, 73-87.

Wood, J.J., Piacentini, J.C., Southam-Gerow, M., Chu, B.C. \& Sigman, M. (2006). Family cognitive behavioral therapy for child anxiety disorders. Journal of the American Academy of Child and Adolescent Psychiatry, 45, 314-321. 
Woodruff-Borden, J., Morrow, C., Bourland, S., \& Cambron, S. (2002). The behavior of anxious parents: Examining mechanisms of transmission of anxiety from parent to child. Journal of Clinical Child and Adolescent Psychology, 31, 364-374. 


\section{Parenting pathways to Child Anxiety}

Parental anxiety accounts for the factor

Parental anxiety raises the risk of the factor adapted from Murray et al (2009) and Creswell et al (2009)

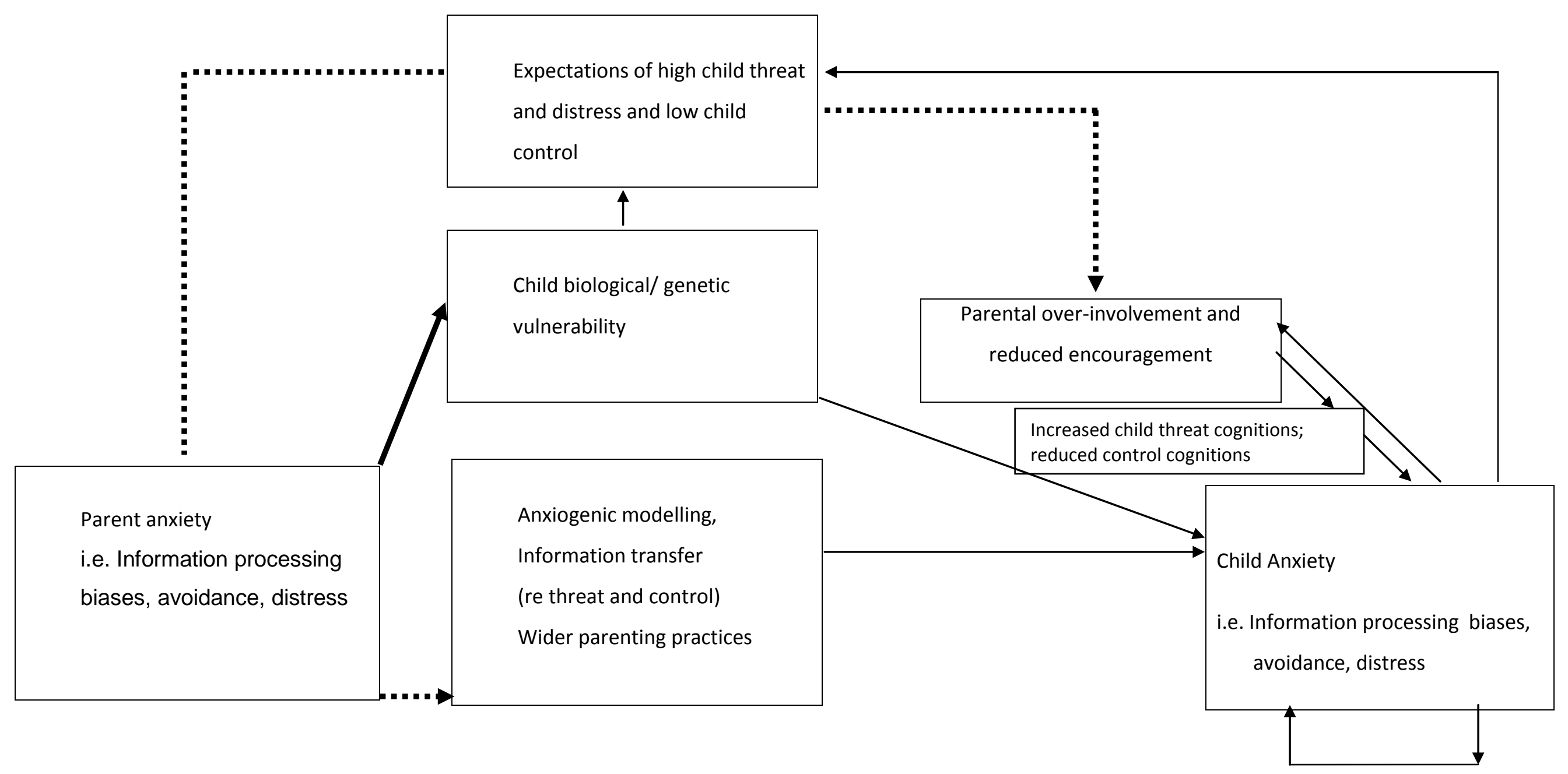

